\title{
Distributed Cognition on the road: Using EAST to explore future road transportation systems
}

\author{
Victoria A. Banks ${ }^{*}$, Neville A. Stanton ${ }^{1}$, Gary Burnett ${ }^{2} \&$ Setia Hermawati $^{2}$ \\ *corresponding author: v.banks@soton.ac.uk \\ ${ }^{1}$ Transportation Research Group, University of Southampton \\ ${ }^{2}$ Human Factors Research Group, University of Nottingham
}

\begin{abstract}
Connected and Autonomous Vehicles (CAV) are set to revolutionise the way in which we use our transportation system. However, we do not fully understand how the integration of wireless and autonomous technology into the road transportation network affects overall network dynamism. This paper uses the theoretical principles underlying Distributed Cognition to explore the dependencies and interdependencies that exist between system agents located within the road environment, traffic management centres and other external agencies in both non-connected and connected transportation systems. This represents a significant step forward in modelling complex sociotechnical systems as it shows that the principles underlying Distributed Cognition can be applied to macro-level systems using the visual representations afforded by the Event Analysis of Systemic Teamwork (EAST) method.
\end{abstract}

Key words: Connected and Autonomous Vehicles: distributed cognition; EAST; network analysis; network metrics 


\section{Introduction}

Over the past two decades, there have been major developments in the integration of wireless and autonomous technologies in the road transportation network (Talebpour \& Mahmassani, 2016). Automated vehicles in particular are quickly becoming an engineering reality (Stanton, 2015) and whilst much research has primarily focussed upon driver-automation interaction (e.g. Banks et al. 2014; Zeeb et al. 2015; Louw \& Merat, 2017), many issues remain. Some of these issues relate to how automation can be regulated, legislated and standardised but more importantly, we do not fully understand how automation will impact overall road system behaviour. For example, Atkins Mobility (2016) speculate that if automation brings about improvements to road safety, we may see a future whereby crash barriers are no longer necessary and roadway signs become redundant as information can be shared using Vehicle-to-Vehicle (V2V) and Vehicle-to-Infrastucture (V2I) communication streams and other location services (e.g. Global Positioning Systems). V2V and V2I is made possible through both the use of Dedicated Short Range Communication (DSRC) sensors and wireless network architectures such as 5G. In vehicles, DSRC represent on-board sensor units whilst external roadside units represent the means to achieve V2I communication. This wireless connectivity would enable intra-vehicle communication as well as real-time communication with traffic management systems. Essentially camera and radar based technologies enable the vehicle to "see" (e.g. vision systems that process video data and fuse with microwave radar data) whilst technologies such as DSRC enables the car to "talk" (i.e., transmit data to other vehicles and infrastructure) and "listen" (i.e., receive data from other vehicles and infrastructure).

The concept of "Connected and Autonomous Vehicles" (CAV) is not new, with research and innovation dating back to the early 1990's (De La Fortelle, 2005). The Science and Technology Select Committee (2017) cite numerous benefits associated with CAV including increased accessibility and mobility, improvements to road safety and congestion. KPMG (2015) hypothesise that by 2030, all new vehicles sold within the United Kingdom will be "fully connected". It is clear then that future transportation systems will be reliant upon the exchange of information between both human and non-human entities to ensure effective system functioning. This type of communicative behaviour is the essence of Distributed Cognition (DCOG; Hutchins, 1995) whereby interactions take place between humans, resources and materials across space and time (Hollan et al, 2000; Hutchins, 1995). DCOG is related to the theory of 'transactional memory' whereby individuals (both human and nonhuman entities) tend to rely upon others to remember things for them (Stanton et al, 2015). Thus, DCOG is characterised by multiple system 'agents' that work together in order to achieve a common goal (Hutchins, 1995). 'Agents' in this sense can receive, hold and share information with one another in order to pursue a common goal (Clark, 1995). This implicates the need for communication and coordination to exist between them (Christoffersen \& Woods, 2002; Stanton, 2014; Eriksson \& Stanton, 2017). Of course, there are many challenges associated with Vehicle-to-Anything (V2X) communication including, but not limited to, issues relating to the size of the network (both in terms of geography and availability). This means that in some instances, the exchange of information between system agents (both human and non-human) may be delayed, inaccurate or incomplete. DCOG provides a theoretical framework that can be used in the effective design of new communication and interactive technologies to support the relationship that exists between 
human and non-human agents by highlighting areas of potential weakness (Hollan et al, 2000). To date, DCOG has only been used to consider small sociotechnical systems in isolation such as an airline cockpit (Hutchins, 1995) and command teams (Stanton, 2014). In this paper, we argue that DCOG provides not only the theoretical foundation, but also the methods, that can be used to explore complex sociotechnical systems at a macro-level.

The road transportation system is a good example of a macro-level sociotechnical system. This is because it can dynamically configure itself to ensure that multiple subsystems acting within it (e.g. Traffic Management Centres work alongside External Agencies) can operate simultaneously to achieve various functions. Thus, the network is based upon a large number of complex interactions and interdependencies between multiple system agents at a number of levels (Salmon et al, 2014). These include system agents within the road environment (e.g. drivers, pedestrians and vehicles), traffic management centres (e.g. traffic management and CCTV operators) and external agencies (e.g. radio stations and emergency services). Whilst these categories of system agent are typically analysed independently, this paper applies the principles underpinning DCOG to all of the agents and agencies involved within the road transportation network. Given the uncertainty of how the transportation network will be affected by CAV functionality, this paper provides a comparison between non-CAV and CAV networks to explore how network dynamism may change as a result of increased connectivity. This comparison is important because it provides initial insights into how system agents will react to, and interact with, intelligent transportation systems.

\section{Method}

DCOG in complex sociotechnical systems can be further explored and understood using the Event Analysis of Systemic Teamwork framework (EAST; Stanton et al, 2008). EAST is a descriptive method that proposes that a system can be described using three inter-linked network representations; task, social and information (Walker et al, 2006; 2010). Task networks provide analysts with a means to show the processes involved in attaining network goals (Salmon et al. 2014). They can provide a description of the sequences and interdependencies that exist between individual subtasks that must be completed to attain these goals. Social networks are used to analyse the structure of the system in terms of the communications that take place between different system 'agents'. Finally, information networks show the information that is used by, and communicated by, system agents during a task (Stanton et al, 2008). Information networks detail aspects of communication that underpin the completion of a task as well as the relationships that exist between these different informational nodes. EAST has been used to focus upon specific tasks within varied domains including aviation (Sorensen et al, 2011), rail (Walker et al, 2006), driving (Banks \& Stanton, 2016) and maritime (Stanton et al, 2006, 2017a, 2017b Stanton 2014; Baber et al, 2013) providing meso-level representations of DCOG (Grote et al, 2014). However, this paper goes further by using the representations afforded by EAST (Stanton et al, 2008) to explore DCOG at a macro-level (Grote et al, 2014). EAST makes it possible to provide an overview of how different agents and agencies within the road transportation network can function simultaneously within a shared space (i.e. the road network). The networks can then be subjected to quantitative analysis using the Applied Graphic and Network Analysis tool (AGNA, version 2.1; Benta, 2005). AGNA is a platform-independent freeware application 
that can be used to analyse task, social and information networks. Nodes within each network can either be analysed individually to assess agent centrality/prominence or as a whole to give an overall impression of system complexity. Network metrics can be used to identify key agents, tasks and informational elements within system operation. Within driving research, the following network metrics have been applied to analyse EAST representations;

Density represents the level of interconnectivity between system agents. It is expressed as a value between 0 and 1, where 0 represents a network that has no connections and 1 indicates that the network is fully connected (Kakimoto et al, 2006). It is calculated using the following formula;

$$
\text { Network density }=2 e / n(n-1)
$$

where $\mathrm{e}=$ total number of links within the network and $\mathrm{n}=$ the number of nodes within the network (Walker et al. 2012).

Diameter is used to analyse the connections and pathways that exist between nodes within the network (Walker et al, 2011). Denser networks (i.e. the route through the network is shorter and more direct) have smaller values. It is calculated using the following formula;

$$
\text { Diameter }=\max _{u y} d\left(n_{i}, n_{j}\right)
$$

where $d\left(n_{i}, n_{j}\right)$ is the "largest number of [agents] which must be traversed in order to travel from one [agent] to another when paths which backtrack, detour, or loop are excluded from consideration” (i.e. max $_{u y}$, Weisstein, 2008; Harary, 1994). Cohesion represents the number of reciprocal connections divided by the total number of possible connections (Stanton, 2014)

Finally, sociometric status provides an indication of agent prominence (Houghton et al, 2006; Salmon et al, 2014). Key agents (i.e. most prominent within the network) have higher sociometric values (Salmon et al, 2012). It is calculated using the following formula;

$$
\text { Sociometric Status }=\frac{1}{g-1} \sum_{j=1}^{g}\left(x_{j i}, x_{i j}\right)
$$

where $g$ is the total number of nodes in the network, $\mathrm{i}$ and $\mathrm{j}$ are individual nodes, $x_{j i}$ are the number of communications between node $\mathrm{j}$ and node $\mathrm{i}$, and $x_{i j}$ are the number of communications between node i and node j (Salmon et al. 2012; Houghton et al. 2006).

\section{Results}

\section{Identification of system agents}

For the purposes of this analysis, a total of 21 system agents were identified from previous work conducted by Price (2016) and Banks \& Stanton (2016). Their work specifically sought to identify system agents involved in Traffic Management operations (e.g. Price, 2016) and within automated driving environments (e.g. Banks \& Stanton, 2016). The 21 agents broadly span three operational categories; Road Environment (RE), Traffic Management Centres (TMC) and External Agencies (EA) (see Table 1 for complete list and descriptions). These agents represent the main human and non-human entities that can be found within the road transportation network. 
Table 1. System agents involved in the road transportation system.

\begin{tabular}{|c|c|c|c|}
\hline Operational Category & Subcategory & Agent & Description \\
\hline \multirow{3}{*}{$\begin{array}{l}\text { Road Environment }(\mathrm{RE})- \\
\text { this category represents all } \\
\text { agents that are present } \\
\text { within the road environment }\end{array}$} & $\begin{array}{l}\text { Drivers (DD / } \\
\text { DM)* }\end{array}$ & $\begin{array}{l}\text { Host Driver } \\
\text { Host Passenger } \\
\text { Other Drivers } \\
\text { Other Passengers } \\
\end{array}$ & $\begin{array}{l}\text { The categories of individuals } \\
\text { occupying vehicles } \\
\text { Role of driver dependent upon } \\
\text { level of automation (DD, DM) }\end{array}$ \\
\hline & $\begin{array}{l}\text { Vehicles } \\
\text { (Connected and } \\
\text { Autonomous } \\
\text { Vehicles; CAV) }\end{array}$ & $\begin{array}{l}\text { Host Vehicle } \\
\text { Other Vehicles } \\
\text { Services/Goods vehicles } \\
\text { Emergency Vehicles }\end{array}$ & $\begin{array}{l}\text { The categories of traffic using } \\
\text { (or potentially using) the road } \\
\text { network } \\
\text { Addition of intelligent sensors } \\
\text { enable CAV function }\end{array}$ \\
\hline & $\begin{array}{l}\text { External Roadside } \\
\text { Equipment (ERE) }\end{array}$ & $\begin{array}{l}\text { Traffic monitoring } \\
\text { equipment } \\
\text { Traffic management } \\
\text { equipment } \\
\text { Vulnerable Road Users } \\
\text { (VRU) } \\
\end{array}$ & $\begin{array}{l}\text { E.g. CCTV cameras and } \\
\text { induction loops } \\
\text { E.g. traffic lights and Variable } \\
\text { Message Signs (VMSs) } \\
\text { E.g. cyclists and pedestrians }\end{array}$ \\
\hline \multirow{4}{*}{\multicolumn{2}{|c|}{$\begin{array}{l}\text { Traffic Management Centre (TMC) - this category } \\
\text { represents all agents that have direct access to } \\
\text { information relating to the overall traffic situation }\end{array}$}} & TMC Operator & Responsible for managing traffic \\
\hline & & $\begin{array}{l}\text { Closed-circuit television } \\
\text { (CCTV) Applications }\end{array}$ & $\begin{array}{l}\text { Controls the TMC's CCTV } \\
\text { cameras }\end{array}$ \\
\hline & & $\begin{array}{l}\text { Urban Traffic } \\
\text { Management Control } \\
\text { (UTMC) Applications }\end{array}$ & $\begin{array}{l}\text { Collects data relating to road } \\
\text { environment (e.g. vehicle } \\
\text { counts) }\end{array}$ \\
\hline & & $\begin{array}{l}\text { Police closed-circuit } \\
\text { television (CCTV) } \\
\text { Personnel }\end{array}$ & $\begin{array}{l}\text { Monitor CCTV for crime, } \\
\text { assisting police operations }\end{array}$ \\
\hline \multirow{5}{*}{\multicolumn{2}{|c|}{$\begin{array}{l}\text { External Agencies (EA) - this category represents } \\
\text { all agents that both share and receive information } \\
\text { relating to traffic situations }\end{array}$}} & Radio Stations & $\begin{array}{l}\text { Distribute information to traffic } \\
\text { and other agents }\end{array}$ \\
\hline & & Information Providers & $\begin{array}{l}\text { Provide additional information } \\
\text { (e.g. Met Office, Highways } \\
\text { England) }\end{array}$ \\
\hline & & $\begin{array}{l}\text { Other transport control } \\
\text { centres }\end{array}$ & $\begin{array}{l}\text { Includes other road TMCs as } \\
\text { well as public transport control } \\
\text { centres (e.g. Bus) }\end{array}$ \\
\hline & & $\begin{array}{l}\text { Emergency services } \\
\text { control centres }\end{array}$ & $\begin{array}{l}\text { Manage emergency } \\
\text { service operations }\end{array}$ \\
\hline & & $\begin{array}{l}\text { Traffic data distribution } \\
\text { services }\end{array}$ & $\begin{array}{l}\text { Dissemination of } \\
\text { information to traffic and third } \\
\text { parties }\end{array}$ \\
\hline
\end{tabular}

* Note DD and DM reflects the "Driver Driving” and "Driver Monitoring” roles identified by Banks \& Stanton (2017).

\section{Task networks}

From the list presented in Table 1, it is possible to consider the types of tasks in which these system agents engage in, and how they may be related. This makes it possible to construct a high level task network for the entire road transportation system involving all 21 agents. Walker et al. (2006) suggest that task networks can show how subtasks may relate to other subtasks based upon their functional or temporal properties.

The task network for the road transportation system, shown in Figure 1, should be viewed as a continuous process to reflect the notion that the system always remains active (i.e. 24 hours a day, 7 days a week). This network representation does not consider any CAV or intelligent 
functionality. The task network portrays the relationships that exist between tasks in a nonsequential manner. Whilst not exhaustive, this representation includes some of the main tasks $(\mathrm{n}=19)$ associated with RE, TMC and EA agents (and the interconnections that may exist between them).

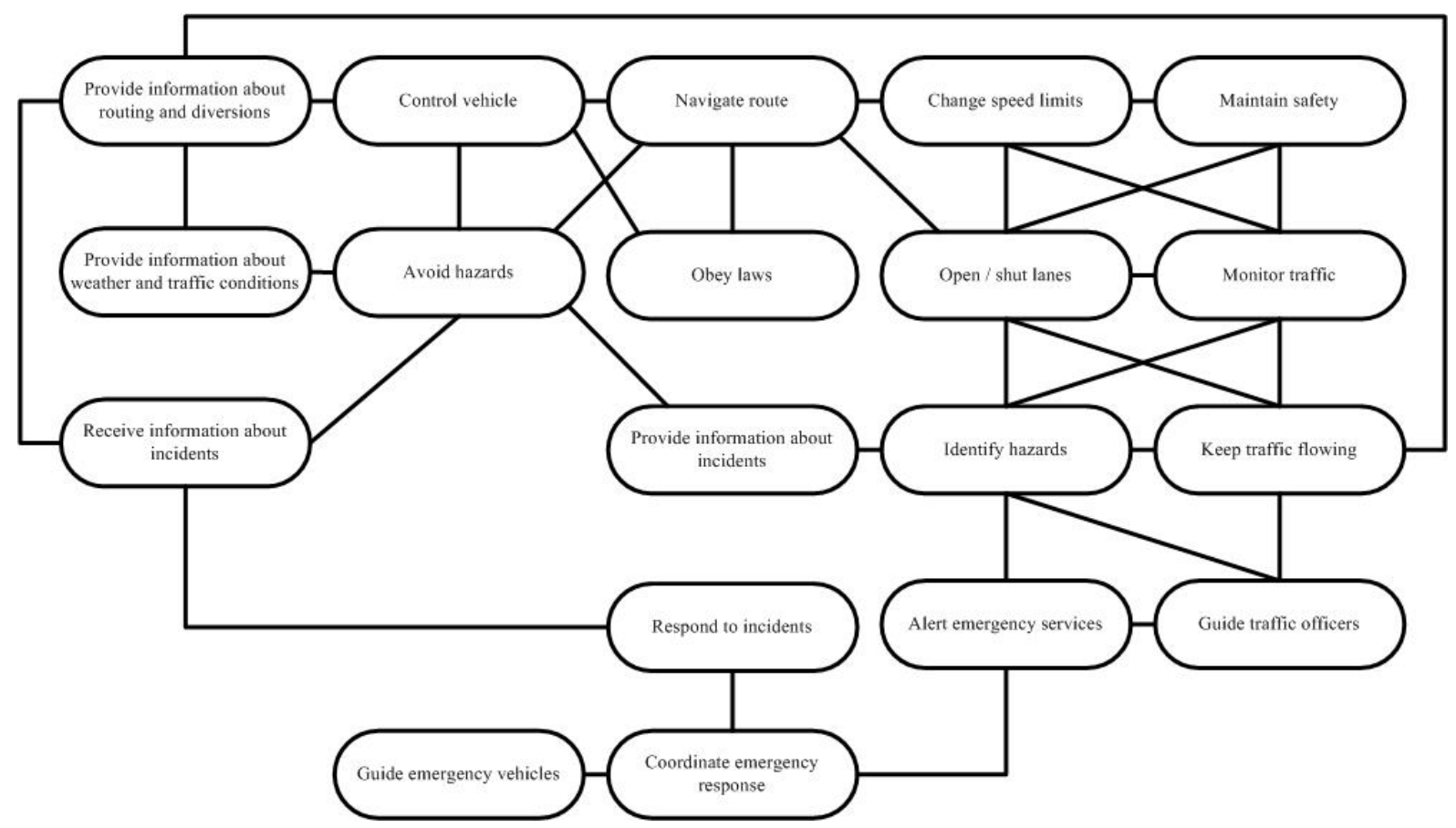

Figure 1. Task network showing high level tasks essential for effective functioning of the road transportation network.

Analysis of the task network presented above was conducted using AGNA (Benta, 2005). The AGNA analysis indicates that the network can be described as binary (i.e. can be represented by a zero-one matrix) and symmetric (i.e. nondirected). In total, the network has 68 connections (i.e. the number of in-out connections between nodes). The network has a diameter of 6 (i.e. six hops from one side of the network to the other) and a density score of 0.2 (i.e. a low distribution network).

However, in order to compare and contrast how non-CAV and CAV task networks may differ, a combined networks approach was adopted (e.g. Stanton, 2014). A combined task and social network approach enables us to see "who" is involved in completing tasks within the transportation network in parallel to keep the task network functioning. In terms of DCOG, this approach provides a means to explore the allocation of system function amongst social agents spanning the RE, TMC and EA categories (outlined in Table 1). For the purposes of discussion, the authors assume that the same basic task network exists regardless of whether intelligent features exist within it. Thus, Figure 2 represents the task network (shown in Figure 1) coded by social agents for a non-CAV network whilst Figure 3 represents the task network for a CAV network - note that subcategories of RE have been added. 
Figure 2 essentially demonstrates that 14 out of 20 tasks are completed in isolation by a single agent category (i.e. RE, TMC or EA). In practical terms, this means that there is a clear division between tasks associated with different agent categories. Importantly, the role of the driver reflected within Figure 2 represents that of "Driver Driving” (DD; Banks \& Stanton, 2017). The DD role essentially represents the idea that the driver is responsible for completing all of the physical and cognitive tasks associated with driving (Walker et al, 2015) and thus responsible for controlling the vehicle, avoiding hazards, navigating routes, obeying laws, monitoring traffic and maintaining safety in the non-CAV network portrayed in Figure 2.

In contrast, Figure 3 represents the task network (coded by social agents) for a CAV network. Here we see many more tasks becoming shared (i.e. completed in parallel by 2 or more agents) in comparison to the non-CAV network. Tasks completed in isolation appear to have halved as a result of CAV implementation. This indicates that the divisions between the RE, TMC and EA categories are less rigid opening up the possibilities to create new communication channels in an effort to improve information sharing and network cohesiveness. 'Task sharing' is particularly more pronounced within the RE category as CAV vehicles are capable of completing the same tasks as a traditional DD. To acknowledge the changing role of the driver within a CAV network, an additional driver role has been added to this network representation. A Driver Monitor (DM) reflects the 'intended' supervisory role of the driver during the intermediate phases of automation (Banks \& Stanton, 2017). A DM would need to continue monitoring the behaviour of the vehicle and automated subsystems despite the transfer of physical control and aspects of decision-making to CAV vehicles. This is to ensure that safe and normal driving practice is maintained. Note that the role of DD remains in the representation to reflect the potential for mixed traffic driving scenarios (e.g. both automated and manually driven vehicles may occupy the road) but also demonstrates further the utility of CAV to perform all of the tasks typically associated with a DD. 


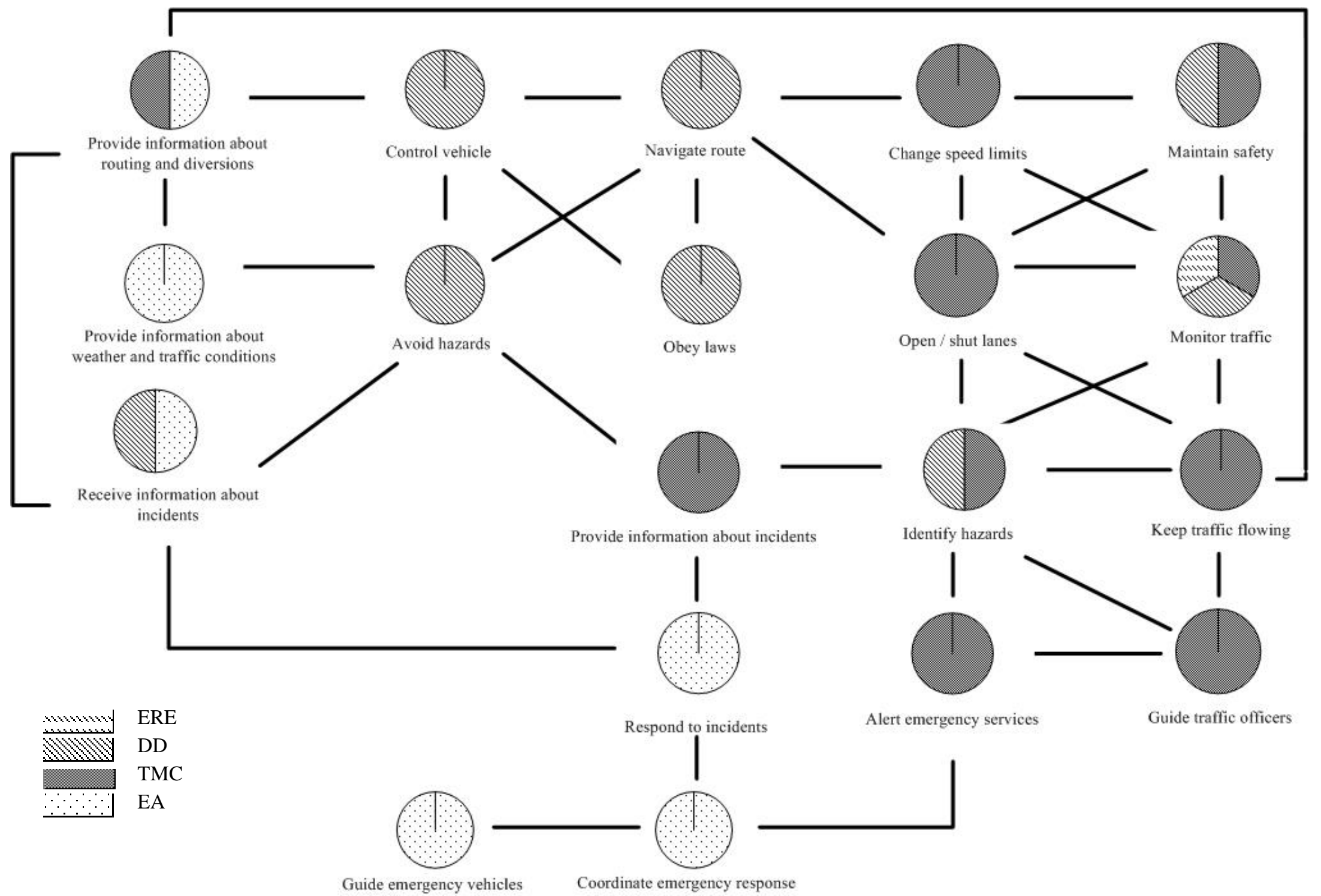

Figure 2. Task network for a non-CAV transportation network coded by social agents. 


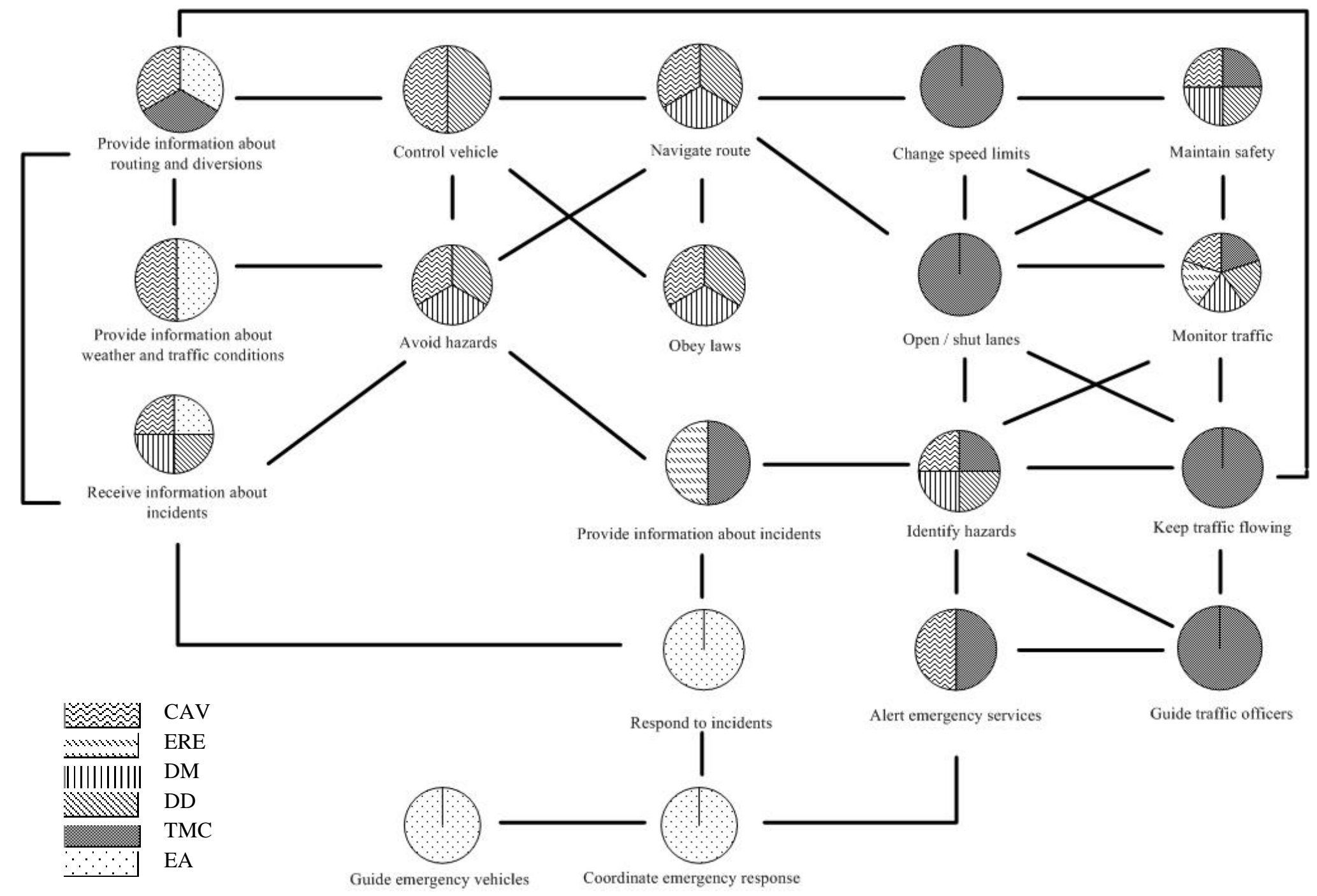

Figure 3. Task network for CAV coded by social agents. 


\section{Social networks}

To better understand the structure of communications that may occur between agents within RE, TMC and EA, social networks were constructed to demonstrate the directional flow of communication between system agents for both non-CAV and CAV networks. Social networks essentially provide a means to assess the relationship (i.e. in terms of communication and activity) between different system agents (Stanton, 2014).

'Communication' between system agents can range from being obvious (e.g. gesture between drivers such as flashing lights, radio broadcasts sharing traffic updates, vehicle can display information on internal interface to alert driver to changes in system status, driver can manipulate controls within vehicle to alter its behaviour) to being 'invisible' (e.g. UTMC data can be used to change behaviour of traffic management equipment). Simplified versions of these networks were then constructed and validated by Subject Matter Experts (SMEs) for ease of interpretation and are presented in Figures 4 and 5. Four SMEs from a leading automotive manufacturer and members of the Human Factors Research Group at the University of Nottingham were involved in this process, with a collective 18 years' experience within the driving automation field.

Figure 4 presents a simplified social network of a non-CAV transportation network. Here, we see that whilst links exist between the RE, TMC and EA, communications typically remain within operational categories. In contrast, Figure 5 presents a social network for future CAV networks and shows that the links that exist between different operational categories become stronger as new links are formed. This is because wireless connectivity between vehicles and infrastructure enables both intra-vehicle, inter-vehicle and real-time communication with traffic management systems. CAV functionality therefore binds the social network more closely together, bridging the ‘communication gap' between different operational categories.

Further analysis of these networks was performed using AGNA (Benta, 2005) to demonstrate that even simplified social network models of macro-level systems can be used to identify differences between agent communications in non-CAV and CAV transportation systems. Table 2 presents the findings of this analysis and shows that whilst the networks have the same number of nodes (i.e. number of system agents), the CAV network incorporates additional connections (i.e. demonstrating the increased communication that exists within the network). The CAV network yields a smaller diameter which is perhaps attributable to the more direct nature of interactions within it. With fewer hops required to get from one side of the network to the other, together with greater network density, CAV implementation does indeed appear to improve network efficiency.

Table 2. Contrasting network metrics for non-CAV and CAV social networks

\begin{tabular}{|l|c|c|}
\hline Social Network Analysis & Non-CAV & CAV \\
\hline Number of nodes (i.e. system agents) & 13 & 13 \\
\hline Number of connections & 43 & 45 \\
\hline Diameter & 5.0 & 4.0 \\
\hline Density & 0.28 & 0.37 \\
\hline
\end{tabular}




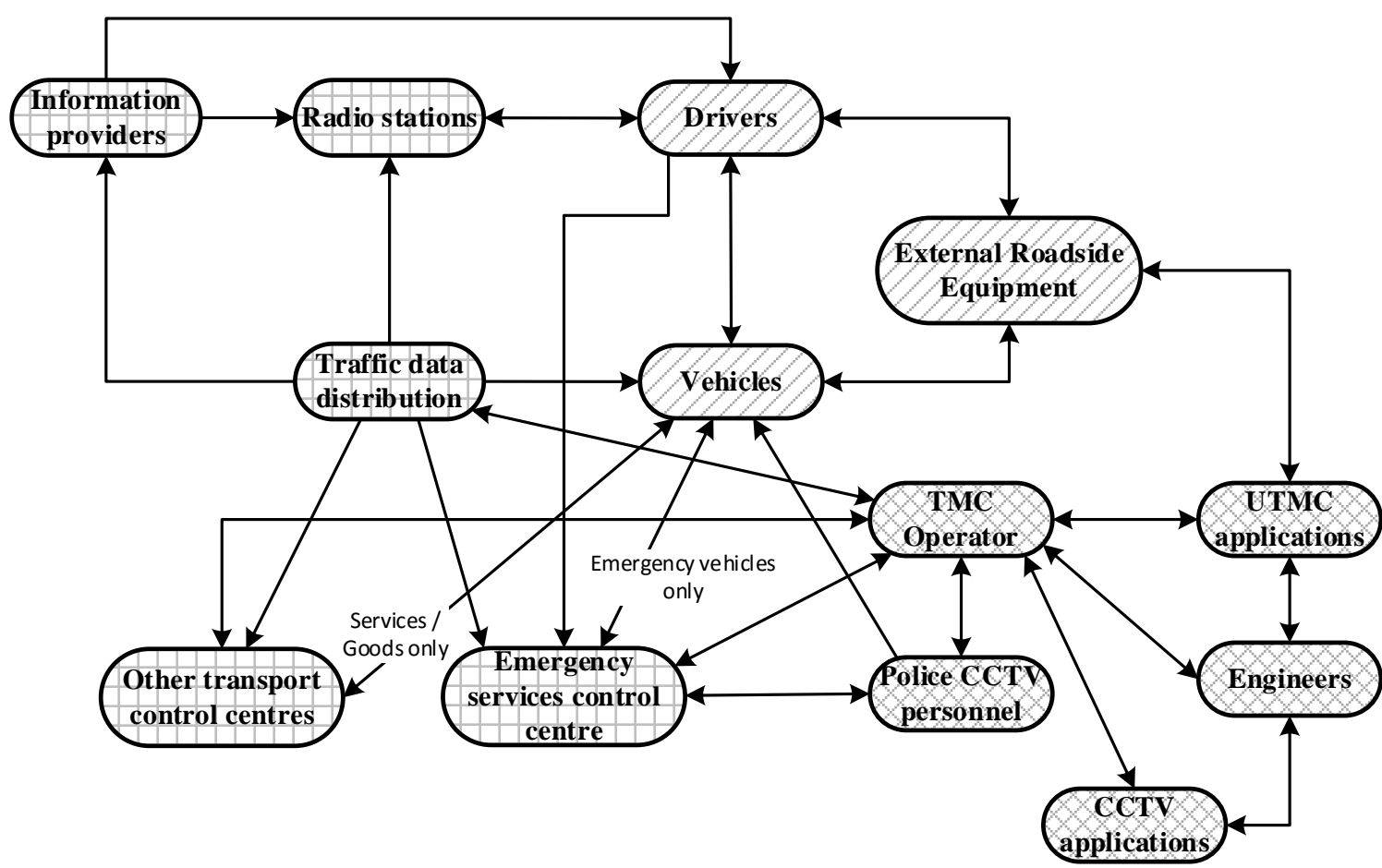

ZZ Road Environment

$\longrightarrow$ External agencies

$\$$ Traffic management centre

Figure 4. Simplified social network representation of macro-level communications within a non-CAV network. 


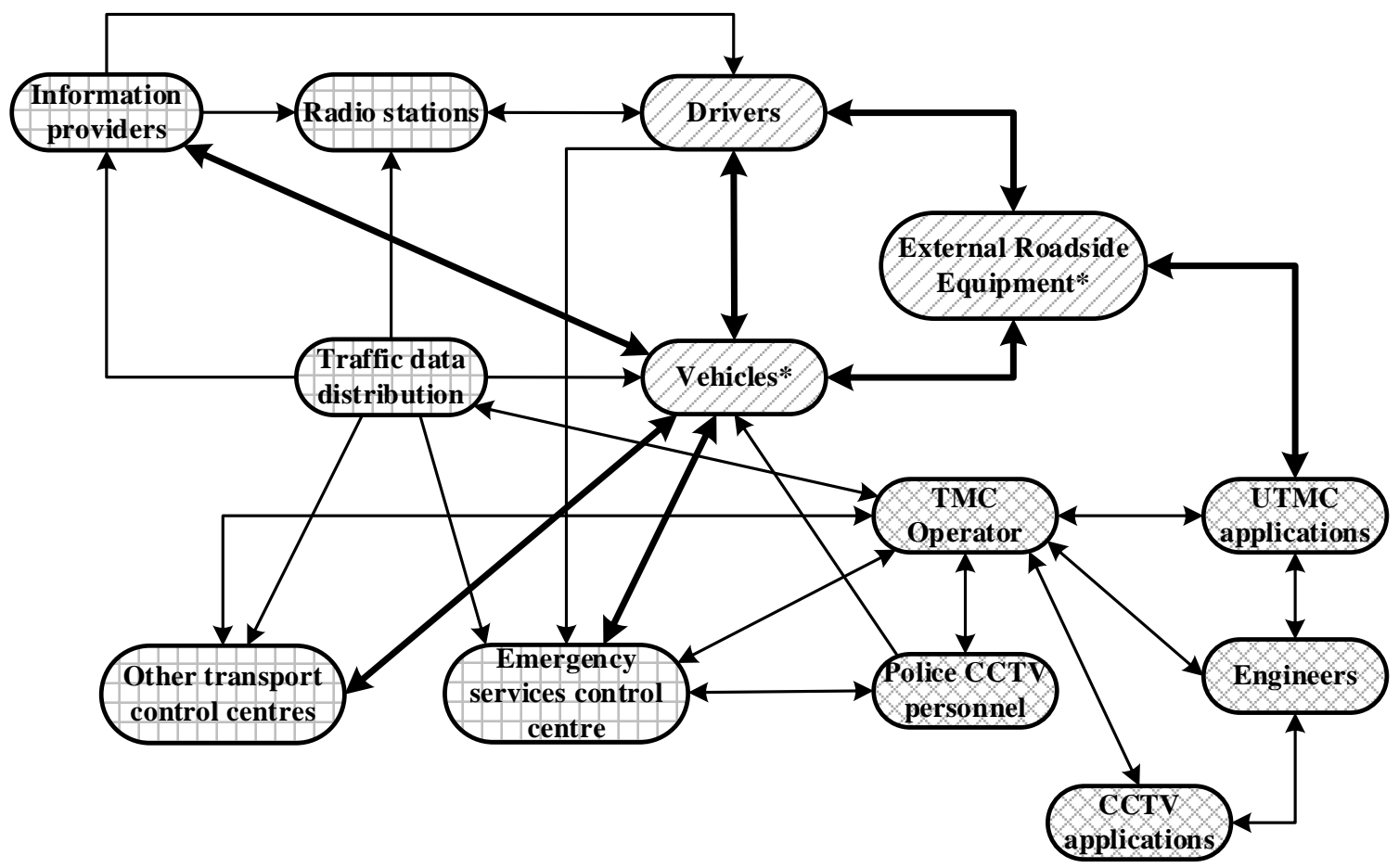

ZOad Environment

$\longrightarrow$ External agencies

$\varnothing$ Traffic management centre

Figure 5. Simplified social network representation of macro-level communications within future CAV networks. Bold lines represent new and strengthened links between agents as a result of CAV implementation.

The calculation of sociometric status was used to assess agent prominence within the networks. To enable us to see the shift in agent prominence occurring as a result of CAV implementation more clearly, only agents holding different sociometric status values between the social networks are highlighted in Table 3. Agents within the RE had the largest changes in prominence. Both 'Vehicle' and 'External Roadside Equipment' categories also gain prominence which is attributable to the introduction of V2V and V2I sensor units. These changes also influence dynamic shifts in other areas of the transportation network, as for example, UTMC becomes even more central to TMC operation. In addition, CAV implementation also strengthens the link between RE and EA agents. 
Table 3. Contrasting sociometric status for agents involved in non-CAV and CAV networks. Highlighted agents yield different sociometric status values as a result of CAV implementation. Asterisks identify ‘key’ agents.

\begin{tabular}{|l|l|c|c|}
\hline Category & \multicolumn{1}{|c|}{ Agent } & $\begin{array}{c}\text { Non-CAV } \\
\text { network }\end{array}$ & CAV network \\
\hline \multirow{2}{*}{$\begin{array}{l}\text { Road } \\
\text { Environment }\end{array}$} & Drivers & $0.67^{*}$ & $1.00^{*}$ \\
\cline { 2 - 4 } & Vehicle & $0.83^{*}$ & $1.67^{*}$ \\
\cline { 2 - 4 } & External Roadside Equipment & 0.50 & $1.00^{*}$ \\
\hline \begin{tabular}{l} 
Traffic $\begin{array}{l}\text { Management } \\
\text { Centres (TMC) }\end{array}$ \\
\cline { 2 - 4 }
\end{tabular} & TMC operator & $1.17^{*}$ & $1.17^{*}$ \\
\cline { 2 - 4 } & CCTV applications & 0.33 & 0.33 \\
\cline { 2 - 4 } & UTMC applications & 0.50 & $0.67^{*}$ \\
\cline { 2 - 4 } & Eolice CCTV personnel & 0.42 & 0.42 \\
\hline \multirow{4}{*}{$\begin{array}{l}\text { External } \\
\text { Agencies (EA) }\end{array}$} & Radio stations & 0.50 & 0.50 \\
\cline { 2 - 4 } & Information providers & 0.33 & 0.33 \\
\cline { 2 - 4 } & $\begin{array}{l}\text { Other transport control } \\
\text { centres }\end{array}$ & 0.42 & 0.42 \\
\cline { 2 - 4 } & $\begin{array}{l}\text { Emergency services control } \\
\text { centres }\end{array}$ & $0.67^{*}$ & 0.58 \\
\cline { 2 - 4 } & Traffic data distribution & $0.58^{*}$ & 0.58 \\
\hline & Mean & 0.55 & 0.73 \\
\cline { 2 - 4 } & & & $0.83^{*}$ \\
\hline
\end{tabular}

\section{Information networks}

The final representational medium within the EAST framework are information networks (Stanton et al, 2008, 2013; Walker et al, 2006; 2010). Information networks detail aspects of communication that underpin the foundations of the system and how they are linked. The process of constructing information networks typically follows the interrogation of operator verbalisations. These may be captured using observational notes, interviews and live audio feeds recorded during task completion (e.g. Walker et al. 2010). Information nodes are identified and then paired with their closest relation. For example, nodes within the same sentence will be linked (e.g. Stanton, 2014; Walker et al. 2010). This strategy quickly builds a network of information concepts (Banks \& Stanton, 2017). According to Stanton (2014), information may be related temporally or spatially to different agents or tasks. The information network presented in Figure 6 was constructed based upon this strategy and combines driver-orientated knowledge (see Banks \& Stanton, 2017) with TMC-orientated knowledge (see Price, 2016) to represent a non-CAV transportation network. This representation contains 53 nodes and 119 connections and demonstrates that in order to ensure the effective functioning of the road transportation network, a plethora of information 
must be captured, processed and distributed between all of the agents involved. In contrast, the information network representing the operation of a CAV network has 18 additional nodes and a further 66 connections (see Figure 7). These additional nodes essentially represent the information that can be generated from the implementation of CAV into the network. 


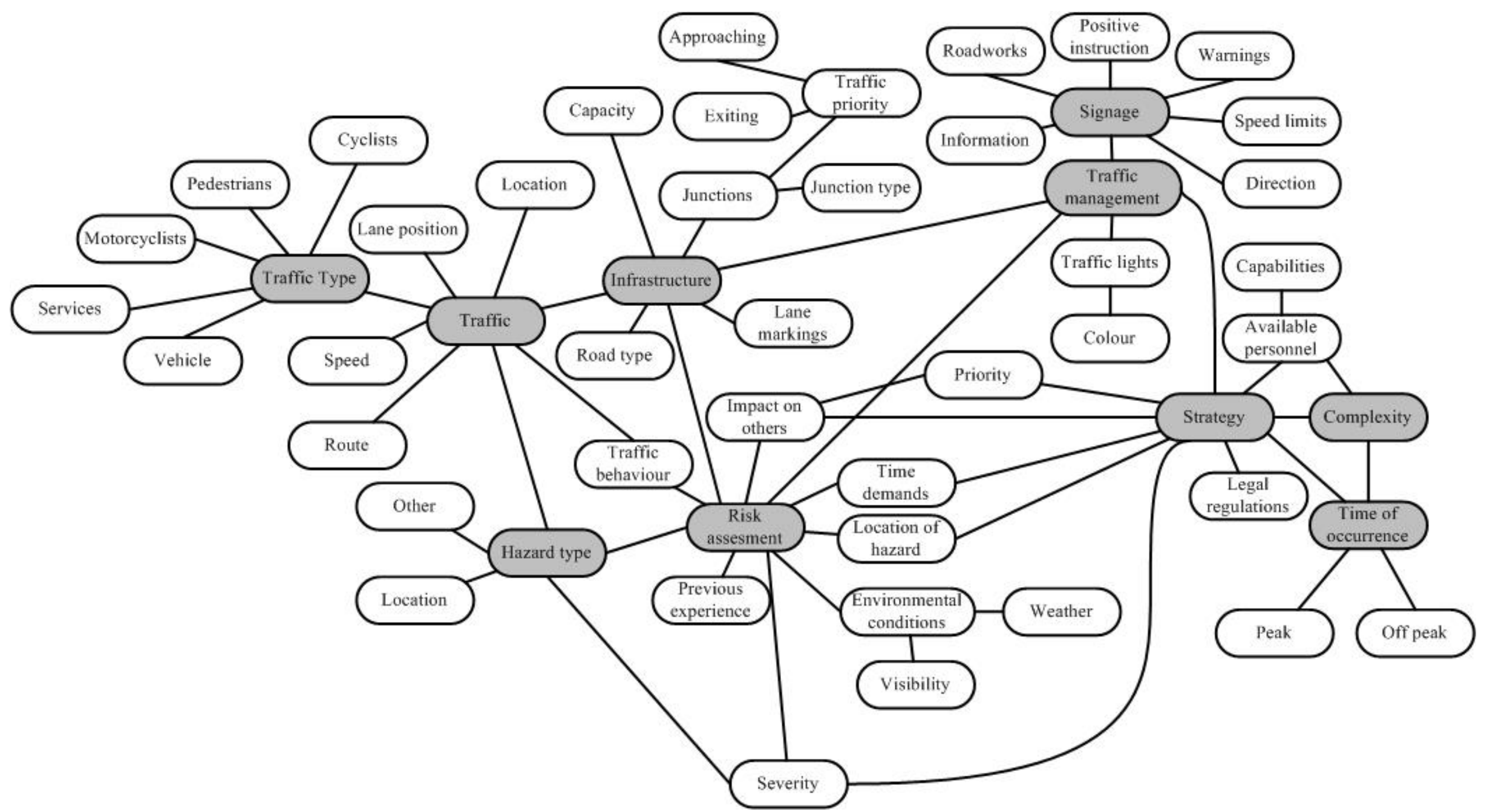

Figure 6. Information network for non-CAV networks (note that 'key' nodes highlighted in grey are based upon the calculation of sociometric status - see Table 5). 


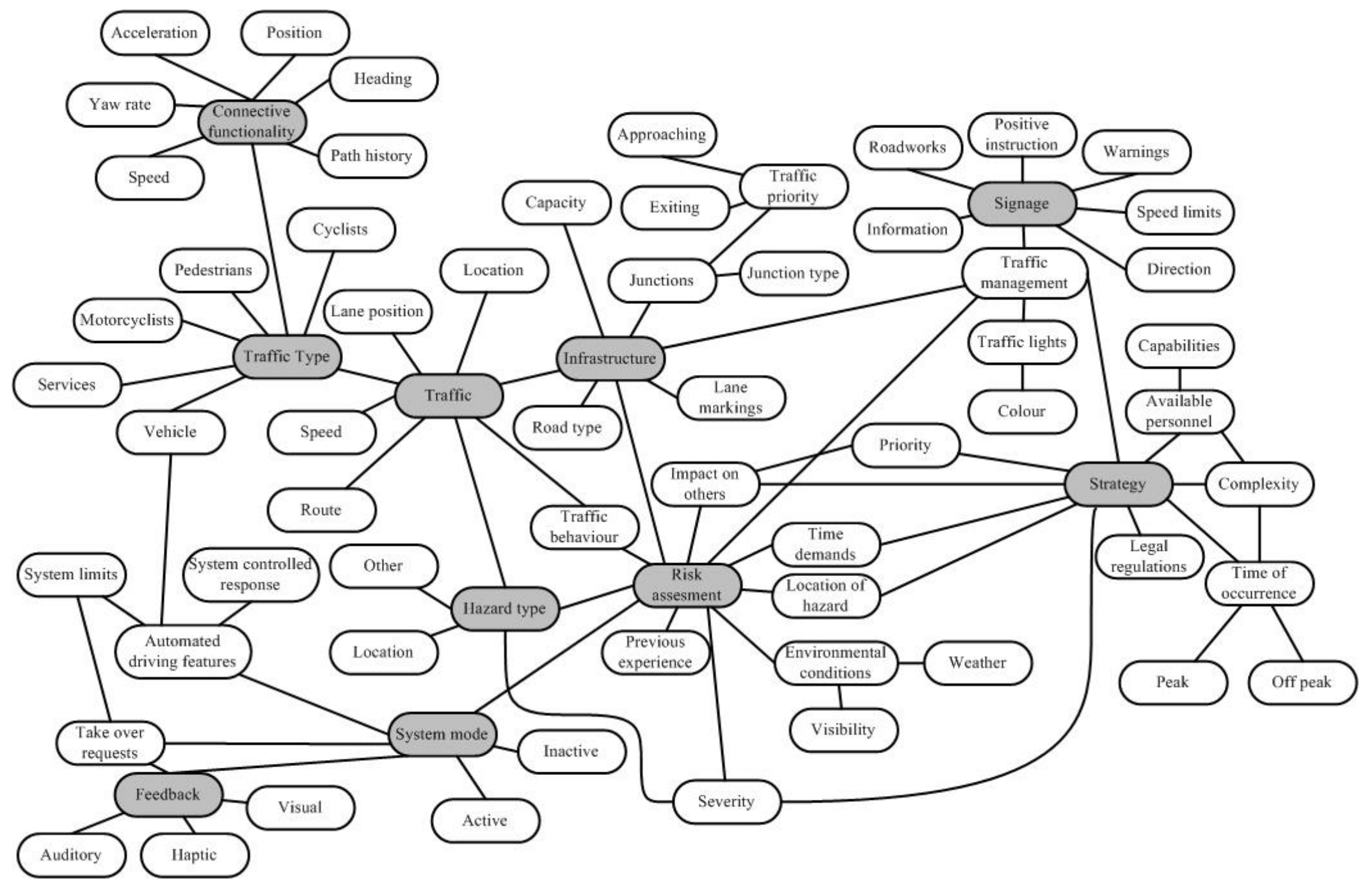

Figure 7. Hypothetical information network for CAV networks (note that 'key' nodes highlighted in grey are based upon the calculation of sociometric status - see Table 5). 
The information networks presented in Figures 6 and 7 were subjected to further analysis using AGNA (Benta, 2005) and show that whilst network dynamism does not significantly change at a global level (see Table 4), the CAV network grows rapidly, even at a high level of analysis.

Table 4. Comparison of network metrics relating to the information networks for non-CAV and CAV networks

\begin{tabular}{|l|c|c|}
\hline Information Network Analysis & Non-CAV & CAV \\
\hline Number of nodes & 53 & 71 \\
\hline Number of connections & 119 & 185 \\
\hline Diameter & 8 & 8 \\
\hline Density & 0.04 & 0.04 \\
\hline
\end{tabular}

Underlying differences between non-CAV and CAV information networks is important because we need to ensure that agents within the network are equipped with 'key' knowledge about its functioning. Sociometric status was calculated to assist in the identification of key informational nodes within the non-CAV and CAV networks above. Data were ranked in descending order to enable the authors to highlight key informational nodes within both nonCAV and CAV information networks. The results are shown in Table 5 and appear to confirm that any node with four or more connections should be considered to play a central role in the knowledge base that underpins effective functioning of the system (Banks \& Stanton, 2017). Table 5 shows that key terminologies within non-CAV and CAV networks remain largely the same although there is greater emphasis upon 'connectivity', particularly in relation to system mode and feedback in CAV networks.

Table 5. Key informational nodes based upon rank sociometric status scores.

\begin{tabular}{|l|l|l|}
\hline & \multicolumn{1}{|c|}{ Non-CAV } & \multicolumn{1}{c|}{ CAV } \\
\hline 1 & Strategy & Connective functionality \\
\hline 2 & Risk assessment & Strategy \\
\hline 3 & Traffic & Risk assessment \\
\hline 4 & Signage & Traffic \\
\hline 5 & Infrastructure & Signage \\
\hline 6 & Traffic type & Infrastructure \\
\hline 7 & Hazard type & Traffic type \\
\hline 8 & Time of occurrence & System mode \\
\hline 9 & Traffic management & Feedback \\
\hline 10 & Complexity & Hazard type \\
\hline
\end{tabular}

\section{Discussion}

This paper presents a practical method for analysing and evaluating DCOG at a macro-level. Unlike previous applications that have tended to explore DCOG in meso-level systems, the authors of this paper have taken a much 'broader' systems view. Rather than isolating a subsystem operating within a much larger sociotechnical system, the authors have taken the 
road transportation system as their 'unit of analysis' (Grote et al, 2014). This in turn provides a macro-level account of DCOG that has enabled us to explore the dependencies and interdependencies that exist between human and non-human agents across different operational domains for both non-CAV and CAV networks.

Inspired by Hutchins (1995), the authors have shown how cognitive processes can be distributed socially across system agents, internal and external tasks and through time (acknowledging that earlier processes may transform the nature of later processing) using EAST. Although EAST has been primarily used to focus upon meso-level activities within varied domains (e.g. Baber et al, 2013; Banks \& Stanton, 2016; Stanton et al. 2006; Stanton, 2014; Walker et al, 2006), this paper shows that network representations can also provide a means to explore macro-level DCOG within much larger sociotechnical systems. Rather than focussing upon an individual component of a system (for example, the RE), the authors have considered other dependencies and interdependencies spanning multiple operational environments (i.e. the inclusion of TMC and EA).

EAST was used to describe non-CAV and CAV networks in terms of task, social and information networks to help improve our knowledge of how these systems may work in practice. Whilst the network representations presented in this paper are by no means exhaustive, they do provide a basis for discussion into: a) the agents that play a role in our road transportation system; b) how these agents are connected to one another; c) the types of communication or information that are shared within the network; and d) how this may change as a result of CAV implementation. Regardless, any new conceptualisation based upon future transportation systems will need to consider the changes on these sociotechnical networks.

The combined task and social network approach using the EAST framework can provide insight into DCOG within the transportation network by identifying "who" is doing "what". It demonstrates that even though the underlying task network for the transportation system remains the same, a connected and autonomous system, can lead to multiple system agents completing the same tasks in parallel. As long as CAV architecture complements existing infrastructures and frameworks that uphold non-CAV networks, tasks spanning the RE, TMC and EA categories could all benefit from CAV implementation. Specifically, CAV should increase the efficiency and reliability of network operations for all social agents involved (Talebpour \& Mahmassani, 2016). However, there are a number of issues that must be considered in order to make CAV networks a success. For example, there remain issues relating to cybersecurity, compatibility of data sharing between different cloud computing platforms and 'car hacking' (e.g. Checkoway et al. 2011; Frost \& Sullivan, 2014). With 'nonhuman' agents set to become the most prominent agents within a CAV network, designers must ensure that cloud computing platforms are both secure, reliable and efficient. They must be capable of holding, processing, selecting and retransmitting relevant information to relevant social agents. A failure within the network could after all have far reaching implications in terms of RE, TMC and EA operations. For example, a loss of network coverage could mean information is shared intermittently, which will affect the reliability and efficiency of the network. It is therefore important to consider the differences between CAV and non-CAV networks because until the network is fully connected (across space and time), transitions between CAV and non-CAV operation are still likely to occur. 
Quantitative analysis of networks using network metrics enables systematic assessment of existing systems (i.e. non-CAV) and future systems (i.e. CAV). The network analysis presented in this paper is rudimentary but arguably provides insight into the distributed nature of system function that has not previously been explored. Network metrics have been used to quantitatively analyse the underlying differences between non-CAV and CAV networks. Sociometric status, in particular, has been useful in identifying key agents or nodes within the networks as well as highlighting how the implementation of CAV can change the prominence of individual agents or nodes. These methods and tools provide a means to explore possible strengths and weaknesses within system function. In the future, EAST may be used to provide further insight into potential network resilience issues via a 'broken-links' approach (Stanton \& Harvey, 2017). After all, it is likely that failure in one part of the CAV network is likely to have a substantial knock-on effect in others, especially if human agents become accustomed to CAV functionality. Perceptions of competence and expectancy can all impact upon the way in which agents interact on the road (e.g. Rudin-Brown \& Parker, 2004).

\section{Conclusions}

Vehicle automation and the connected services in which they offer appear set to revolutionise the way in which people interact with and behave within the road transportation network. Essentially, CAV points to a future whereby most, if not all, of the potential communication links between vehicles and infrastructure within the RE may be connected. Thus, rather than CAV eliminating Ergonomics and Human Factors issues from the transportation network entirely, it could actually increase the importance of them as it highlights the types of activities human and non-human agents will engage in. Whilst networked simulators exist, enabling multiple drivers to interact in a single virtual environment, research outputs are limited to a single operational environment (e.g. Sawyer \& Hancock, 2012). Thus, it has only been possible to explore how intelligent transport systems, such as CAV, will impact individual agents involved within the road environment. EAST goes further than this and provides a framework that can enable researchers to visualise the impact of CAV on a much larger scale. Adopting socio-technical systems design in this way could offer a means to improve the performance of the whole system rather than individual components in isolation (Stanton, 2014). Modelling system interaction between system agents can provide an extensive qualitative overview of DCOG within large-scale network operations.

\section{References}

Atkins Mobility. 2016. “Connected \& autonomous vehicles: Introducing the future of mobility.” Available at http://www.atkinsglobal.co.uk . Accessed 10.01.2017.

Baber, C, N A Stanton, J Atkinson, R McMaster, and R J Houghton. 2013. "Using social network analysis and agent-based modelling to explore information flow using common operational pictures for maritime search and rescue operations.” Ergonomics 56 (6): 889-905.

Banks, V. A, and N A Stanton. 2016. "Driver-centred vehicle automation: Using network analysis for agentbased modelling of the driver in highly automated driving systems.” Ergonomics 59(11): 1442-1452.

Banks, V A, N A Stanton, and C Harvey. 2014. "Sub-systems on the road to vehicle automation: Hands and feet free but not 'mind' free driving.” Safety Science 62: 505-514.

Banks, V, A, and N A Stanton. 2017. "Going from a 'Driver Driving' to a 'Driver Monitoring' and back again: Modelling driving automation using EAST”. Theoretical Issues in Ergonomics Science.

Benta, M. 2005. “Studying communication networks with AGNA 2.1.” Cognition Brain Behaviour 9: 567-574. Checkoway, S, D McCoy, B Kantor, D Anderson, H Shacham, S Savage, K Koscher, A Czeskis, F Roesner, and T Kohno. 2011. "Comprehensive Experimental Analyses of Automotive Attack Surfaces.” Proceedings of USENIX Security Symposium. San Francisco. 
Christoffersen, K, and D D Woods. 2002. "How to Make Automated Systems Team Players.” Advances in Human Performance and Cognitive Engineering Research 2: 1-12.

De La Fortelle, A. 2005. "Cybercars: Past, present and future of the technology." $12^{\text {th }}$ Word Congress on Intelligent Transport Systems. San Francisco, USA.

Eriksson, A, and N A Stanton. 2017. "Takeover time in highly automated vehicles: Noncritical transitions to and from manual control”. Human Factors. DOI: 10.1177/0018720816685832.

European Road Transport Research Advisory Council (ERTRAC). 2015. "ERTRAC Automated Driving roadmap, July 2015.” Accessed 12 13, 2016.

Frost \& Sullivan. 2014. “Cybersecurity in the Automotive Industry.” 30 October. Accessed 01 09, 2017. http://www.frost.com.

Grote, G., Stanton, N. A. and Weyer, J. 2014. “Beyond Human-Centred Automation”. Ergonomics, 57 (3), 289-294.

Harary, F. 1994. “Graph Theory”. Reading, MA: Addison-Wesley.

Hollan, J, E Hutchins, and D Kirsh. 2000. "Distributed cognition: Toward a new foundation for humancomputer interaction research.” ACM Transactions on Computer Human Interaction 7: 174-196.

Houghton, R J, C Baber, R McMaster, N A Stanton, P M Salmon, R Stewart, and G H Walker . 2006. "Command and control in emergency services operations: A social network analysis." Ergonomics 49: 1204-1225.

Hutchins, E. 1995. “How a cockpit remembers its speeds.” Cognitive Science 19 (3): 265-288.

KPMG. 2015. "Connected and autonomous vehicles - the UK economic opportunity.” Available at https://www.smmt.co.uk/wp-content/uploads/sites/2/CRT036586F-Connected-and-AutonomousVehicles-\%E2\%80\%93-The-UK-Economic-Opportu...1.pdf.

Lavrinc, D. 2014. This is how bad self-driving cars suck in the rain. http://jalopnik.com/this-is-how-bad-selfdriving-cars-suck-in-the-rain-.

Louw, T. and Merat, N. 2017. "Are you in the loop? Using gaze dispersion to understand driver visual attention during vehicle automation.” Transportation Research Part C: Emerging Technologies 76: 35-50

Price, J. 2016. "Human factors in the design of traffic management systems" University of Southampton, Faculty of Engineering and the Environment, UK, 2016. EngD thesis.

Rudin-Brown, C M, and H A Parker. 2004. "Behavioural adaptation to adaptive cruise control (ACC): Implications for preventative strategies.” Transportation Research Part F, 7 (2): 59-76.

Salmon, P M, M G Lenne, G H Walker, N A Stanton, and A Filtness. 2014. "Using the Event Analysis of Systemic Teamwork (EAST) to explore the conflicts between different road user groups when making right hand turns at urban intersections.” Ergonomics 57 (11): 1628-1642.

Sawyer, B D, and P A Hancock. 2012. "Development of a linked simulation network to evaluate intelligent transportation system vehicle to vehicle solutions.” Proceedings of the Human Factors and Ergonomics Society Annual Meeting, 56 (1): 2316-2320.

Science and Technology Select Committee. 2017. “Connected and autonomous vehicles: The future?” Available at: https://www.publications.parliament.uk/pa/ld201617/ldselect/ldsctech/115/115.pdf.

Society for Automotive Engineers. 2016. Taxonomy and defintiions for terms related to on-road motor vehicle automated driving systems. Accessed 12 12, 2016. http://standards.sae.org/j3016_201401/.

Sorensen, L J, N A Stanton, and A P Banks. 2011. "Back to SA school: Contrasting three approaches to situation awareness in the cockpit.” Theoretical Issues in Ergonomics Science 12 (6): 451-471.

Stanton, N A. 2014. "Representing distributed cognition in complex systems: How a submarine returns to periscope depth.” Ergonomics 57 (3): 403-418.

Stanton, N A. 2015. “Responses to autonomous vehicles.” Ingenia 62: 9.

Stanton, N. A., Baber, C. and Harris, D. 2008. Modelling Command and Control: Event Analysis of Systemic Teamwork. Ashgate: Aldershot.

Stanton, N A, and C Harvey. 2017. Beyond human error taxonomies in assessment of risk in sociotechnical systems: A new paradigm with the EAST 'broken-links' approach. Ergonomics.

Stanton, N. A. and Roberts, A. P. J. (2017a) Examining task, social and information networks in submarine command and control. IEEE Transactions on Human-Machine Systems, doi: 10.1109/THMS.2017.2720659.

Stanton, N. A., Roberts, A. P. J. and Fay, D. T. (2017b) Up periscope: Understanding submarine command and control teamwork during a simulated return to periscope depth. Cognition, Technology and Work, 19 (2-3), 399-417.

Stanton, N A, P M Salmon, L Rafferty, G H Walker, C Baber, and D P Jenkins. 2013. Human factors methods: A practical guide for engineering and design. Aldershot: Ashgate.

Stanton , N A, P M Salmon, and G H Walker . 2015. "Let the reader decide: A paradigm shift for situation awareness in sociotechnical systems.” Journal of Cognitive Engineering and Decision Making 9 (1): 44-50. 
Stanton, N A, R Stewart, D Harris, R J Houghton, C Baber , R McMaster, P M Salmon, et al, 2006. "Distributed situation awareness in dynamic systems: Theoretical development and application of an ergonomics methodology.” Ergonomics 49 (12-13): 1288-1311.

Talebpour, A, and H S Mahmassani. 2016. Influence of connected and autonomous vehicles on traffic flow stability and throughput. Transportation Research Part C: Emerging Technologies 71: 143-163.

Walker, G H, H Gibson, N A Stanton, C Baber, P Salmon, and D Green. 2006. "Event analysis of systematic teamwork (EAST): A novel integration of ergonomic methods to analyse C4i activity.” Ergonomics 49 (12-13): 1345-1369.

Walker, G H, N A Stanton, C Baber, L Wells, H Gibson, P Salmon, and D Jenkins. 2010. "From ethnography to the EAST method: A tractable approach for representing distributed cognition in Air Traffic Control." Ergonomics 53 (2): 184-197.

Walker, G H, N A Stanton, and P M Salmon. 2015. Human factors in automotive engineering and technology. Aldershot: Ashgate.

Weisstein, E. W. 2008. "Graph diameter”. From MathWorld-A Wolfram Web Resource. Available at: http://mathworld.wolfram.com/GraphDiameter.html. Accessed on $6^{\text {th }}$ Oct 2017.

Zeeb, K., Buchner, A., and Schrauf, M. 2015. "What determines the take-over time? An integrated model approach of driver take-over after automated driving.” Accident Analysis \& Prevention 78:212-221. 